\title{
DIAGNOSTIC AND GENDER DIFFERENCES IN THE EXPRESSED FEARS OF ANXIOUS PATIENTS
}

\author{
BRUCE A. THYER, PATRICIA TOMLIN, GEORGE C. CURTIS, \\ OLIVER G. CAMERON and RANDOLPH NESSE
}

The Department of Psychiatry, The University of Michigan Hospitals

\begin{abstract}
Summary - Fear Survey Schedule data are presented for a sample of 141 psychiatric patients who met the DSM-III criteria for an anxiety disorder. Diagnostic and gender differences in expressed fears are presented and the results are discussed in light of previous research.
\end{abstract}

Almost from the inception of behavioral research and therapy, pencil and paper inventories have been employed in the assessment of anxiety response patterns for both analog subjects and clinical patients (Dickson, 1975). A large number of such inventories have been developed but the most extensively utilized and validated instrument is the Fear Survey Schedule (FSS) of Wolpe and Lang (1977). The FSS consists of a list of 108 potential anxiety evoking stimuli (objects, animals or situations) which the patient is asked to rate in terms of the fear they provoke. A five-point rating scale ranging from 0 (no fear) to 4 (extreme fear) is employed and a patient's total score may range from 0 to 432 . The temporal stability of the total score of the instrument based upon a 16-week test-retest period with untreated agoraphobic patients was respectable $(r=0.90$, from Michelson and Mavissakalian, 1983). Construct (Landy \& Gaupp, 1971; Arrindell, 1980) and convergent validity (Geer, 1965; Grossberg and Wilson, 1965; Suinn, 1969; Hannah, Storm and Caird, 1965; Lang and Lazovik, 1963) also appear to be high, and the instrument predicts phobic avoidance behavior (Lanyon and Manosevitz, 1966; Paul, 1966; Kamil, 1970; Fazio, 1969; Lick, Sushinsky and
Malow, 1977). In addition, normative data are available for the FSS based upon patients with a DSM-III anxiety disorder (Tomlin, Thyer, Curtis, Nesse, Cameron and Wright, 1984) and for college students (Fischer and Turner, 1978) as well. Reviews by Hersen (1973) and Wolpe and Lang (1977) present more detailed descriptions of the use of fear survey schedules and other self-report measures of anxiety.

One consistent fear survey schedule finding is that adult females score significantly higher than do adult males over the test as a whole (Geer, 1965; Wilson, 1967a; Manosevitz and Lanyon, 1965; Grossberg and Wilson, 1965; Bernstein and Allen, 1969; Hersen, 1973; Lawlis, 1971). This difference occurs as early as ages 9-12 years (Scherer and Nakamura, 1968). This differential pattern of expressing phobic anxiety does not appear to be the result of differential physiological responsiveness to phobic stimuli between men and women (Katkin and Hoffman, 1976; Wilson, 1967b, 1966; Neufeld and Davidson, 1974), nor apparently due to a strong social desirability component of the inventories (Geer, 1965; Farley and Mealiea, 1971), although Wilson (1967a) found that the "silly" fears (e.g. moths and worms) were reported almost exclusively by women, while

Requests for reprints should be addressed to: Bruce A. Thyer, Ph.D., School of Social Work, Florida State University, Tallahassee, FL 32306, U.S.A. 
fears of truly dangerous things such as sharks and heights were reported comparatively more often by males.

Almost all of the previous research involving fear survey schedules was conducted prior to the development of the third edition of the Diagnostic and Statistical Manual of Mental Disorders (American Psychiatric Association, 1980). The current manual (DSM-III) is a significant departure from its predecessor, the DSM-II (American Psychiatric Association, 1968 ) in that some diagnostic categories were eliminated (e.g. anxiety state), whereas others were more clearly delineated (e.g. agoraphobia with, and without, panic attacks), or newly developed (e.g. panic disorder; generalized anxiety disorder). Some differential patterns in the pervasiveness and impact of phobic anxiety evoking stimuli would be expected in anxious patients assessed using the current nomenclature. For example, the DSM-III requires, for the diagnosis of agoraphobia with or without panic attacks, the clinician to determine that ". . f fears or avoidance behavior dominate the individual's life"' (American Psychiatric Association, 1980, p. 227). With simple and social phobia, however, the patient need not have his life dominated by the fear, only that he experience significant distress in the presence of the anxiety evoking stimulus. In panic disorder, the phenomenonology is almost totally subjective and is described as being only ". . . rarely incapacitating" (American Psychiatric Association, 1980, p. 230).
The present study examined FSS responses of a group of DSM-III diagnosed anxious patients in order to determine the extent of diagnostic and gender differences in their expressed fears.

\section{METHOD}

\section{Subjects}

The sample consisted of patients seen for evaluation and treatment at the Anxiety Disorders Program of the Department of Psychiatry at the University of Michigan Hospitals. Information pertaining to each patient's diagnosis, FSS score and age were culled from the clinic file. All patients given a DSV-III diagnosis by a faculty psychiatrist of either simple or social phobia, obsessive-compulsive disorder. panic disorder or agoraphobia with panic attacks seen between 1979 and 1981, and who had completed the Wolpe and Lang (1977) FSS, are included in the study. The sample consisted of 104 females and 37 males, each group with a mean age of 36 years.

\section{RESULTS}

Data pertaining to the samples' gender and diagnostic distribution, and their total Fear Survey Schedule score, are presented in Table 1.

A two-sample $t$-test performed on the mean total FSS scores for males and females failed to reach significance $[t \quad(139)=1.64 ; P=0.10]$, although a trend in the direction of women expressing more fears is evident. An analysis of variance of the total FSS scores, by diagnosis, demonstrated statistically significant differences $[F(4,136)=7.63 ; p<0.001]$, indicating a differential pattern in the expressed

Table 1. Total mean Fear Survey Schedule for the overall sample, and separately by gender

\begin{tabular}{lrrrrrrrrrr}
\hline & \multicolumn{3}{c}{ Overall } & \multicolumn{3}{c}{ Females } & \multicolumn{4}{c}{ Males } \\
\hline Diagnosis & F & M Score & S.D. & N & M & S.D. & N & M & S.D. \\
Simple phobia & 64 & 89.9 & 53.5 & 51 & 89.7 & 55.2 & 13 & 90.6 & 48.6 \\
Social phobia & 20 & 86.9 & 63.5 & 10 & 83.1 & 65.6 & 10 & 90.6 & 64.6 \\
Agoraphobia & 34 & 152.0 & 58.9 & 29 & 161.0 & 58.2 & 5 & 99.6 & 30.6 \\
Obsessive Compulsive & 11 & 117.6 & 43.1 & 9 & 122.2 & 45.5 & 2 & 96.5 & 33.2 \\
Panic disorder & 12 & 113.5 & 61.4 & 5 & 128.4 & 71.7 & 7 & 112.8 & 56.4 \\
Total sample & 141 & 108.6 & 61.5 & 104 & 113.6 & 64.5 & 37 & 94.5 & 50.2 \\
\hline
\end{tabular}


Table 2. Scheffe post-hoc paired contrasts of total FSS Scores, between diagnostic groups

\begin{tabular}{lcccccc}
\hline 1. Agoraphobia & - & & & & \\
2. Panic disorder & N.S. & - & & & \\
3. Obsessive-compulsive & N.S. & N.S. & - & & \\
4. Social phobia & 0.001 & N.S. & N.S. & - & \\
5. Simple phobia & 0.001 & N.S. & N.S. & N.S. & - \\
& 1. & 2. & 3 & 4. & 5. \\
\hline
\end{tabular}

fears of anxious patients. Scheffe post hoc paired comparisons of the differences in the total FSS scores occurring between the diagnostic groups are presented in Table 2 and clearly indicate that patients diagnosed as simple or social phobic score significantly lower than agoraphobic patients. In contrast, the diagnoses of simple and social phobia, obsessive compulsive disorder and panic disorder are statistically indistinguishable from one another based upon their expressed fears. A sex by diagnostic group ANOVA performed upon the total FSS scores exceeded chance expectations $[F(9,131)=4.10 ; P<0.001]$, but Scheffe post hoc comparisons found that the only significant difference in total FSS scores occurred between the female agoraphobics and female simple phobics.

Female patients scored significantly higher ( $P<0.05$ or less) than the male patients on 19 of the 108 FSS items, including being alone, loud voices, crossing streets, being in a strange place, automobiles, thunder, bats, journeys by train, dead animals, weapons, journeys by bus, crawling insects, mice or rats, darkness, nude men, nude women, harmless spiders, large open spaces, and leaving home. The male patients' item scores significantly exceeded the females' scores on only three items, lightning, sight of knives or sharp objects, and ideas of possible homosexuality.

The 10 most fear provoking stimuli as rated separately by male and female patients are listed in Table 3 . What appears most interesting is the remarkable degree of congruence between men and women among these 10 stimuli; both groups of patients rated the same nine items as among the 10 most fearful things or experiences they could encounter. A similar study conducted 15 years ago by Rothstein and Boblitt (1970) employing 100 psychiatric inpatients reported similar findings. Rothstein and Boblitt's (1970) patients produced a list of their "highest fcar" items, and for both men and women the ratings contained six FSS items identical to those chosen by our own patient sample (see Table 3 ). There were no significant gender differences occurring between the scores on any of the 10 items chosen by the patients in the present study, suggesting that men and women possess more similarities than differences with respect to the types of stimuli they find anxiety evoking. On the individual FSS items which did demonstrate gender differences, the absolute value of the patients' scores were on the lower end of the anchoring scale, usually between 0 (not at all) and 1 (a little). This suggests that among anxious patients, the frequent report of gender differences in expressed fears may represent a statistically significant artifact rather than a clinically meaningful finding.

\section{DISCUSSION}

These findings challenge commonly accepted clinical lore. Despite our large sample size, no clear gender differences appeared in the total FSS scores of anxious patients, although a trend was evident in the direction of a higher score for women. This suggests that as a group, fermale patients do not exhibit clinically significantly different fears than do male patients. Gender differences, when they do 
Table 3. Rankings of the top 10 mean fear scores for female and male anxious patients

\begin{tabular}{|c|c|c|c|c|}
\hline \multirow[t]{2}{*}{ Rank } & \multicolumn{2}{|l|}{ Females } & \multicolumn{2}{|l|}{ Males } \\
\hline & FSS Item & Mean Score & FSS Item & Mean Score \\
\hline 1. & Prospects of a surgical operation & 2.23 & Speaking in public* & 2.24 \\
\hline 2. & Speaking in public & 2.23 & Losing control of yourself* & 2.21 \\
\hline 3. & Losing control of yourself* & 2.19 & Failure* & 2.13 \\
\hline 4. & Feeling rejected by others* & 2.12 & Feeling rejected by others* & 2.08 \\
\hline 5. & Failure* & 2.04 & Looking foolish & 2.05 \\
\hline 6. & Looking down from high buildings & 2.03 & Prospect of surgical operation* & 1.97 \\
\hline 7. & Looking foolish* & 1.89 & Feeling disapproved of & 1.94 \\
\hline 8. & Hurting the feelings of others & 1.86 & Hurting the feelings of others & 1.91 \\
\hline 9. & Journeys by airplane & 1.86 & Looking down from high buildings & 1.83 \\
\hline 10. & Feeling disapproved of* & 1.78 & Thoughts of being mentally ill & 1.81 \\
\hline
\end{tabular}

*This factor was also listed among the top ten fears by 50 female and 50 male psychiatric inpatients by Rothstein and Boblitt (1970).

occur, are generally of small magnitude and of little practical relevance. Male and female patients demonstrate a remarkable degree of similarity in the 10 stimuli which they fear most, selecting nine common elements out of a pool of 108 FSS items.

Diagnostic differences do occur in total FSS responses and these are primarily attributable to female patients with a diagnosis of agoraphobia with panic attacks versus simple phobia. This is congruent with previous research remarking on the massive phobic impairments characteristic of agoraphobia as a whole, relative to patients with other anxiety disorders (Marks, 1969).

Other anxiety disorders such as simple or social phobia appear to exert a much less pervasive impact upon a patient's life. The handicaps associated with severe obsessive-compulsive disorder typically involve a preoccupation with internal cues such as intrusive thoughts or the performance of ritualistic behavior. These may or may not be connected to phobic stimuli such as the fear of germs prompting repetitive washing, but generally speaking, our obsessive-compulsive disorder and panic disorder patients expressed fewer fears than our agoraphobics. Our diagnostic assignments were made on the basis of patients' clinical features, not on their scores on the FSS or other psycho- metric instruments we employ. Nevertheless, our results support the DSM-III convention that agoraphobics, as a whole, are severely handicapped by their phobic impairments.

\section{RFFERF.NCF.S}

American Psychiatric Association (1968) Diagnostic and Statistical Manual of Mental Disorders (2nd ed.). American Psychiatric Association, Washington, D.C.

American Psychiatric Association (1980) Diagnostic and Statistical Manual of Mental Disorders (3rd ed.). American Psychiatric Association, Washington, D.C.

Arrindell W. A. (1980) Dimensional structure and psychopathology correlates of the Fear Survey Schedule (FSS-III) in a phobic population: A factorial definition of agoraphobia, Behav. Res. Ther. 18, 229-242.

Bernstein D. A. and Allen G. J. (1969) Fear survey schedule (II): Normative data and factor analyses based upon a large college sample, Behav. Res. Ther. 7, 403-407.

Dickson C. R. (1975) Role of assessment in behavior therapy. In Advances in Psychological Assessment (Edited by McReynolds P.). Jossey-Bass, San Francisco.

Farley F. H. and Mealiea W. L. (1971) Dissimulation and social desirability in the assessment of fears, Behav. Ther. 2, 101-102.

Fazio A. F. (1969) Verbal and overt-behavioral assessment of a specific fear, J. Consult Clin. Psychol. 33, 705-709.

Fischer S. and Turner R. (1978) Standardization of the Fear Survey Schedule, J. Behav. Ther. \& Exp. Psychiat. 9, 129-133.

Geer J. H. (1965) The development of a scale to measure tear, Behav. Res. Ther. 3, 45-53.

Grossberg J. M. and Wilson H. K. (1965) A correlational comparison of the Wolpe-Lang Fear Survey Schedule and the Taylor Manifest Anxiety Scale, Behav. Res. Ther. 3, 125-128. 
Hannah F., Storm T. and Caird W. K. (1965) Sex differences and relationships among neuroticism, extraversion and fears, Perceptual and Motor Skills 20, 1214-1216.

Hersen M. (1973) Self-assessment of fear, Behav. Ther. 4. $241-257$.

Kamil L. J. (1970) Psychodynamic changes through systematic desensitization, J. abnorm. Psychol. 76, 199-205.

Katkin E. S. and Hoffman L. S. (1976) Sex differences and self-report of fear: A psychophysical assessment, J. abnorm. Psychol. 85, 607-610.

Landy F. J. and Gaupp L. A. (1971) A factor analysis of the Fear Survey Schedule III, Behav. Res. Ther. 9, 89-93.

Lang P. J. and Lazovik A. D. (1963) Experimental desensitization of a phobia, J. abnorm. soc. Psychol. 66, 519-525.

Lanyon R. I. and Manosevitz M. (1966) Validity of selfreported fear, Behav. Res. Ther, 4, 259-263.

Lawlis G. F. (1971) Response styles of a patient population on the Fear Survey Schedule, Behav. Res. Ther. 9. 95-102.

Lick J. R., Sushinsky L. W. and Malow R. (1977) Specificity of Fear Survey Schedule items and the prediction of avoidance behavior, Behav. Mod. 1, 195-203.

Manosevitz M. and Lanyon R. I. (1965) Fear Survey Schedule: A normative study, Psychol. Rep. 17, 699-703.

Marks I. M. (1969) Fears and Phobias. Heinemann, London.

Michelson L. and Mavissakalian M. (1983) Temporal stability of self-report measures in agoraphobia research, Behav. Res. Ther. 21, 695-698.
Neufeld R. W. J. and Davidson P. O. (1974) Sex differences in stress response: A multivariate analysis, $J$. abnorm. Psychol. 85, 607-610.

Paul G. L. (1966) Insight versus Desensitization in Psychotherupy: An Experiment in Anxiety Reduction. Stanford University Press, Palo Alto, California.

Rothstein W. and Boblitt W. E. (1970) Expressed fears of psychiatric inpatients, J. clin. Psychol. 26, 277-279.

Scherer M. W, and Nakamura C. Y. (1968) A fear survey schedule for children (FSS-FC): A factor analytic comparison with manifest anxiety, Behav. Res. Ther. 6. 173-182.

Suinn R.M. (1969) The relationship between fears and anxiety: A further study, Behav. Res. Ther. 7, 317-318.

Tomlin P., Thyer B. A., Curtis G. C., Nesse R., Cameron O. and Wright P. (1984) Standardization of the Fear Survey Schedule based upon patients with DSM-I!I anxiety disorders, J. Behav. Ther. \& Exp. Psychiat. $15,123-126$.

Wade T. D. (1978) Factor analytic approaches to the investigation of common fears: A critical appraisal and reanalysis. Behav. Ther. 9, 923-935.

Wilson G. D. (1966) An electrodermal technique for the study of phobia, N. Z. Med. J. 65, 696-698.

Wilson G. D. (1967a) Social desirability and sex differences in expressed fear, Behav. Res. Ther. 5, 136-137.

Wilson G. D. (1967b) GSR responses to fear-related stimuli, Perceptual and Motor Skills 24, 401-402.

Wolpe J. and Lang P. (1977) Monual for the Fear Survey Schedule. EdITS, San Diego, Calif. 